Journal of Advanced Research in Fluid Mechanics and Thermal Sciences

\title{
Synthesis and Characterisation of Pyridinium-Based Ionic Liquid as Activating Agent in Rubber Seed Shell Activated Carbon Production for $\mathrm{CO}_{2}$ Capture
}

\author{
Nawwarah Mokti ${ }^{2}$, Azry Borhan ${ }^{1,}{ }^{*}$, Siti Nur Azella Zaine2 ${ }^{2}$ Hayyiratul Fatimah Mohd Zaid ${ }^{2}$ \\ 1 HICOE, Centre for Biofuel and Biochemical Research, Institute of Self-Sustainable Building, Department of Chemical Engineering, Universiti \\ Teknologi PETRONAS, Seri Iskandar, 32610, Perak, Malaysia \\ 2 Department of Chemical Engineering, Universiti Teknologi PETRONAS, Seri Iskandar, 32610, Perak, Malaysia
}

\section{ARTICLE INFO}

\section{Article history:}

Received 16 December 2020

Received in revised form 13 March 2021

Accepted 20 March 2021

Available online 14 April 2021

\section{Keywords:}

Activated carbon (AC); Ionic Liquid (IL); 1 butylpyridinium bis

(trifluoromethylsulfonyl) imide [C4Py] $\left[\mathrm{Tf}_{2} \mathrm{~N}\right]$; Nuclear Magnetic Resonance (NMR); Fourier Transform Infrared Spectroscopy (FTIR); Rubber seed shell (RSS)

\section{ABSTRACT}

\begin{abstract}
The use of an activating agent in chemical activation of activated carbon (AC) production is very important as it will help to open the pore structure of $A C$ as adsorbents and could enhance its performance for adsorption capacity. In this study, a pyridinium-based ionic liquid (IL), 1-butylpyridinium bis (trifluoromethylsulfonyl) imide, $\left[\mathrm{C}_{4} \mathrm{Py}\right]\left[\mathrm{Tf}_{2} \mathrm{~N}\right]$ has been synthesized by using anion exchange reaction and was characterized using few analyses such as ${ }^{1} \mathrm{H}-\mathrm{NMR},{ }^{13} \mathrm{C}-\mathrm{NMR}$ and FTIR. Low-cost AC was synthesized by chemical activation process in which rubber seed shell (RSS) and ionic liquid $\left[\mathrm{C}_{4} \mathrm{Py}\right]\left[\mathrm{Tf}_{2} \mathrm{~N}\right]$ were employed as the precursor and activating agent, respectively. $\mathrm{AC}$ has been prepared with different IL concentration ( $1 \%$ and $10 \%)$ at $500^{\circ} \mathrm{C}$ and $800^{\circ} \mathrm{C}$ for 2 hours. Sample AC2 shows the highest $\mathrm{S}_{\mathrm{BET}}$ and $\mathrm{V}_{\mathrm{T}}$ which are $392.8927 \mathrm{~m}^{2} / \mathrm{g}$ and $0.2059 \mathrm{~cm}^{3} / \mathrm{g}$ respectively. The surface morphology of synthesized AC can be clearly seen through FESEM analysis. A high concentration of IL in sample AC10 contributed to blockage of pores by the IL. On the other hand, the performance of synthesized AC for $\mathrm{CO}_{2}$ adsorption capacity also studied by using static volumetric technique at 1 bar and $25^{\circ} \mathrm{C}$. Sample AC2 contributed the highest $\mathrm{CO}_{2}$ uptakes which is $50.783 \mathrm{~cm}^{3} / \mathrm{g}$. This current work shows that the use of low concentration IL as an activating agent has the potential to produce porous AC, which offers low-cost, green technology as well as promising application towards $\mathrm{CO}_{2}$ capture.
\end{abstract}

\section{Introduction}

Over the few past years, the emission of carbon dioxide, $\mathrm{CO}_{2}$ in our environment kept increasing day by day and thus causing global warming and climate change. Human activities such as the combustion of fossil fuels are one of the major contributors to the emission of $\mathrm{CO}_{2}$ into the environment. This issue has gained attention among researchers to study for $\mathrm{CO}_{2}$ capture technologies such as absorption, adsorption, cryogenic and membrane separations. Among these, the most conventional method for the emission of $\mathrm{CO}_{2}$ in the environment is amine-absorption using

\footnotetext{
* Corresponding author.

E-mail address: azrybo@utp.edu.my

https://doi.org/10.37934/arfmts.82.1.8595
} 
MEA, DEA and MDEA as solvents. However, this technology has a few disadvantages such as high heat capacity and energy consumption, corrosion in equipment used and caused foaming $[10,13,20,25]$. Therefore, the new evolution had attempted to overcome this problem. As a result, the development of environmentally friendly, low capital and operating cost and high thermal stability has been given much attention in group researchers. Adsorption techniques by using solid adsorbent from biomass such as activated carbon (AC) is one of the promising alternatives to increase the $\mathrm{CO}_{2}$ adsorption.

AC is widely used and applied in many applications such as adsorption of heavy metals, decolorization, purification, catalysis, catalytic support, electrochemical capacitor and gas storage $[8,12]$. AC has many advantages such as low cost, highly porous structure, firm and stable in shape, has a broad surface area with high adsorption capacity, organized macro, meso and microporous structure and a high degree of surface reactivity $[8,22]$. Besides, biomass-based AC offers high their abundantly available, cheap, renewable, easy processing, high volume applications, less abrasive to equipment, low cost for waste disposal and reduces waste produced [12]. There are many literature studies used biomass as their precursor in converting into AC such rice straw matter, olive stones, nutshells, coffee grounds and rubber seed shell (RSS) and many more [3,4,11,12,17,21,31]. AC can be produced via physical or chemical activation. Traditionally, chemical activation by using excess of chemical agents such as $\mathrm{ZnCl}_{2}, \mathrm{H}_{3} \mathrm{PO}_{4}$ and $\mathrm{KOH}$ before undergoes carbonization step under inert condition at temperature between $500^{\circ} \mathrm{C}$ to $800^{\circ} \mathrm{C}$ is much more preferred due to its offer may advantages such as gives high surface area, more porous structure and high surface adsorption capacity $[1,4,8,16]$. Besides their advantages, they also have disadvantages such as chemical used is not environmentally friendly and can cause corrosion towards the equipment used [2].

Recently, ionic liquid (IL) have been applied in $\mathrm{CO}_{2}$ application. IL have been reported exhibiting good attractive properties such as have melting point less than $100^{\circ} \mathrm{C}$, not flammable which means not easily to burn, good ionic conductivity, have negligible low vapour pressure, have a high stability both chemically and thermally and acts as good solvent with widely varying polarity such as polar and non-polar [14,24,37]. Additionally, IL also can be considered as a safe, clean and environmentally friendly solvent and also known as "green solvents" [26,33,37]. IL is mainly composed of cations and anions and these combinations can be tuneable depending on the specific chemical applications. Previously, $\mathrm{CO}_{2}$ capture by using imidazole-based IL pairing has extensively used with different anions. Anion nature plays a primary role in $\mathrm{CO}_{2}$ solubility. The fluorinated anion such as $\mathrm{Tf}_{2} \mathrm{~N}, \mathrm{PF}_{6}$ and $\mathrm{BF}_{4}$ will give a higher affinity towards $\mathrm{CO}_{2}$ capture than other anions such as $\mathrm{N}(\mathrm{CN})_{2}$ and $\mathrm{NO}_{3}$ [32]. Despite high $\mathrm{CO}_{2}$ solubility, it also has a major problem such as the viscosity of IL itself thus limit the mass transfer of between $\mathrm{CO}_{2}$ gas and IL [15].

Besides, IL itself also can be as precursors to produce porous carbon [23]. However, the use of IL as an activating agent in the production of AC using biomass as a precursor are still very scarce. Herein, we present pyridinium-based IL, 1-butylpyridinium bis (trifluoromethylsulfonyl) imide, $\left[\mathrm{C}_{4} \mathrm{Py}\right]\left[\mathrm{Tf}_{2} \mathrm{~N}\right]$ as an activating agent to produce porosity on the surface of AC. Besides, this pyridiniumbased IL offers low cost and toxicity, high thermal stability and biodegradable and high $\mathrm{CO}_{2}$ solubility compared to imidazolium-based IL [34]. Anion like $\operatorname{Tf}_{2} \mathrm{~N}$ is chosen as it can act as pyrogens in which help in the formation of pore [18]. In this study, the production of AC was varied with different concentrations of $\mathrm{IL}$ and temperature including tested with $\mathrm{CO}_{2}$ adsorption to prove low concentration of IL can be one of the activating agents to replace conventional activating agents including offers as a better adsorbent for $\mathrm{CO}_{2}$ capture application. 


\section{Experimental}

\subsection{Materials and Reagents}

The chemicals and solvent used in the synthesis of $\left[\mathrm{C}_{4} \mathrm{Py}\right]\left[\mathrm{Tf}_{2} \mathrm{~N}\right] \mathrm{IL}$ are pyridine $(109728$, Merck, $\geq$ 99.5\%), 1-bromobutane (801602, Merck, $\geq 98 \%$ ), ethyl acetate (109623, Merck, 99.5\%), lithium bis (trifluoromethanesulfonyl)imide, LiTf $2 \mathrm{~N}$ (544094, Sigma Aldrich, $\geq 95 \%$ ) and ethanol (64-17-5, HmbG, 95\%). All chemicals were used without any drying and further purification. Rubber seed shell (RSS) collected from a local rubber plantation, Institut Petanian Titi Gantong, Perak was used as a precursor material in this study.

\subsection{Synthesis of Ionic Liquid}

For the preparation of 1-butylpyridinium bis (trifluoromethylsulfonyl) imide, [ $\left.\mathrm{C}_{4} \mathrm{Py}\right]\left[\mathrm{Tf}_{2} \mathrm{~N}\right] \mathrm{IL}$, two steps procedure was used as reported by Enayati and Faghihian [9] and Yunus et al., [36].

The first step for the preparation of 1-butylpyridinium bromide, $\left[\mathrm{C}_{4} \mathrm{Py}\right][\mathrm{Br}]$ was quaternization reaction. Under nitrogen atmosphere, a mixture of pyridine $(0.5 \mathrm{~mol})$ and 1-bromobutane $(0.55 \mathrm{~mol})$ in ethyl acetate was refluxed and stirred $50^{\circ} \mathrm{C}$ for $72 \mathrm{~h}$ until a white precipitate was formed. The white precipitate was washed with ethyl acetate for several times and then dried in a rotary evaporator at $70^{\circ} \mathrm{C}$ and finally vacuum oven for $24 \mathrm{~h}$ to remove an excess of solvent.

The second step for the preparation of $\left[\mathrm{C}_{4} \mathrm{Py}\right]\left[\mathrm{Tf}_{2} \mathrm{~N}\right]$ was anion exchange reaction. In this step, an equimolar mixture of $\left[\mathrm{C}_{4} \mathrm{Py}\right][\mathrm{Br}]$ and $\mathrm{LiTf}_{2} \mathrm{~N}$ in deionized water was stirred at room temperature for $24 \mathrm{~h}$. The aqueous phase was removed from the product and then the product was washed several times with deionized water until it is free from halogenated ion. The product was then dried in a rotary evaporator at $70^{\circ} \mathrm{C}$ for several hours and finally vacuum oven at $50^{\circ} \mathrm{C}$ for $72 \mathrm{~h}$ to ensure complete removal of water content in the product.

\subsection{Preparation and Carbonization of RSS}

Firstly, the fresh RSS was washed repeatedly with distilled water to remove all dust and foreign materials before drying at $110^{\circ} \mathrm{C}$ overnight. Then, these dried RSS were crushed, grinded and sieved to a particle size of $1 \mathrm{~mm}$. Subsequently, the sieved RSS were kept into an airtight container until further use for the experimental work. For activation, samples were impregnated with different concentrations of IL which are $1 \%$ and $10 \%(1 \mathrm{~g}$ and $10 \mathrm{~g})$ in $100 \mathrm{~mL}$ of ethanol. Ethanol was used to provide homogeneity during the impregnation process. About $10 \mathrm{~g}$ of RSS was used for the preparation of each sample. The mixture was mixed in a Schott bottle with constant stirring at room temperature for 24 hours to ensure the IL is fully adsorbed into RSS. Then, the mixture was filtered and dried at $110^{\circ} \mathrm{C}$ overnight in an oven, before carbonization process. The impregnated RSS was carbonized in a tubular furnace at $500^{\circ} \mathrm{C}$ and $800^{\circ} \mathrm{C}$ under a steady flow of nitrogen gas for 2 hours. Afterward, the produced $A C$ was cooled at room temperature before washed a few times with warm distilled water until pH between $6.5-7$ is achieved. Later, the $A C$ was dried at $110^{\circ} \mathrm{C}$ overnight in an oven and was kept into an airtight container for characterization. 


\subsection{Sample Characterization \\ 2.4.1 Ionic liquid characterization}

The purity and chemical structure of $\left[\mathrm{C}_{4} \mathrm{Py}\right]\left[\mathrm{Tf}_{2} \mathrm{~N}\right]$ IL was verified by using Nuclear Magnetic Resonance, NMR (Bruker Avance $500 \mathrm{MHz}$ spectrometer). A sample size of $\leq 10 \mathrm{mg}$ was used and dissolved in $\sim 0.6 \mathrm{~cm}^{3}$ of deuterated methanol solvent (MeOD). The ${ }^{1} \mathrm{H}$ NMR and ${ }^{13} \mathrm{C} N M R$ spectra were recorded at room temperature in terms of chemical shifts and multiplicities. The chemical shift denoted as $\delta$ and reported in parts per million (ppm) while spin multiplicities are abbreviated as $s$ (singlet); $d$ (doublet), $t$ (triplet) and $m$ (multiplet). The surface functional groups of [C4Py][Tf $\left.{ }_{2} \mathrm{~N}\right]$ IL were analyzed by using Fourier Transform Infrared Spectroscopy, FTIR (Perkin Elmer Spectrum One). The spectra were recorded between 4000 to $400 \mathrm{~cm}-1$ resolution in the transmission mode.

\subsubsection{Activated carbon characterization}

The surface area and porosity of AC samples were evaluated by using Micromeritics ASAP 2020 (Micromeritics Instruments). Before analysis, each AC sample was degassed at $200^{\circ} \mathrm{C}$ for 16 hours to eliminate all the moisture and contaminant from the surface. The specific surface area of the $A C$ samples was calculated by using Brunauer-Emmett-Teller (BET) equation from nitrogen adsorption isotherm. The total pore volume was determined evaluated at $\mathrm{P} / \mathrm{P}_{\circ}$ of 0.99 . Besides, the surface morphology was analyzed by using Field Emission Scanning Electron Microscopy, FESEM (ZEISS Microscopy).

\section{$2.5 \mathrm{CO}_{2}$ Adsorption Study}

$\mathrm{CO}_{2}$ adsorption study of the AC samples was studied using High Pressure Volumetric Analyzer II, HPVA (Micromeritics Instruments) static volumetric analyzer at 1 bar and $25^{\circ} \mathrm{C}$. Each AC sample was degassed at $200^{\circ} \mathrm{C}$ for 16 hours before adsorption measurements. The volumetric method was described by Rashidi et al., [30].

\section{Result and Discussion}

\subsection{Characterization of $\left[\mathrm{C}_{4} \mathrm{Py}\right]\left[\mathrm{Tf}_{2} \mathrm{~N}\right]$ Ionic Liquid}

\subsubsection{FTIR spectra}

The FTIR spectra of pure $\left[\mathrm{C}_{4} \mathrm{Py}\right][\mathrm{Br}]$, $\mathrm{Li}\left[\mathrm{Tf}_{2} \mathrm{~N}\right]$ and $\left[\mathrm{C}_{4} \mathrm{Py}\right]\left[\mathrm{Tf}_{2} \mathrm{~N}\right]$ are shown in Figure 1. As reported by Enayati and Faghihian [9] and Zhang et al., [38] for $\left[\mathrm{C}_{4} \mathrm{Py}\right][\mathrm{Br}] \mathrm{IL}$ as in Figure 1(a), the butylpyridinium, $\mathrm{C}_{4}$ Py cation characteristic can be observed at: $3133 \mathrm{~cm}^{-1}, 3041 \mathrm{~cm}^{-1}$ (aromatic $\mathrm{C}-\mathrm{H}$ ), $2961 \mathrm{~cm}^{-1}, 2939 \mathrm{~cm}^{-1}, 2873 \mathrm{~cm}^{-1}$ (aliphatic C-H), $1632 \mathrm{~cm}^{-1}$ (aromatic C-C), $1486 \mathrm{~cm}^{-1}, 772 \mathrm{~cm}^{-1}\left(-\mathrm{CH}_{3}\right.$ ), $683 \mathrm{~cm}^{-1}\left(-\mathrm{CH}_{2}\right)$, and for $\mathrm{Br}$ anion at : $571 \mathrm{~cm}^{-1}(\mathrm{C}-\mathrm{Br})$. Besides, as demonstrated by Ramesh and $\mathrm{Lu}$ [27], there are some important peaks in FTIR spectra of pure Li $\left[\mathrm{Tf}_{2} \mathrm{~N}\right]$ and these can be seen in Figure 1(b). The bis (trifluoromethylsulfonyl) imide, $\mathrm{Tf}_{2} \mathrm{~N}$ anion can be observed at: $1346 \mathrm{~cm}^{-1}, 1325 \mathrm{~cm}^{-1}$, $1131 \mathrm{~cm}^{-1}\left(\mathrm{C}-\mathrm{SO}_{2}-\mathrm{N}\right), 1189 \mathrm{~cm}^{-1}\left(-\mathrm{CF}_{3}\right), 1059 \mathrm{~cm}^{-1}(\mathrm{~S}=\mathrm{O}), 799 \mathrm{~cm}^{-1}$ (combination of C-S and S-N), 747 $\mathrm{cm}^{-1}(\mathrm{~S}-\mathrm{N})$. As a result, the desired $\left[\mathrm{C}_{4} \mathrm{Py}\right]\left[\mathrm{Tf}_{2} \mathrm{~N}\right] \mathrm{IL}$ shows an evidence for the appearance of the cation and anion characteristics from the previous precursor salt, $\left[\mathrm{C}_{4} \mathrm{Py}\right][\mathrm{Br}]$ and $\mathrm{Li}\left[\mathrm{Tf}_{2} \mathrm{~N}\right]$ using anion exchange reaction. The band can be observed and summarized as per Table 1 . Therefore, the above result proved that the desired ionic liquid which is $\left[\mathrm{C}_{4} \mathrm{Py}\right]\left[\mathrm{Tf}_{2} \mathrm{~N}\right] \mathrm{IL}$ was successfully synthesized. 


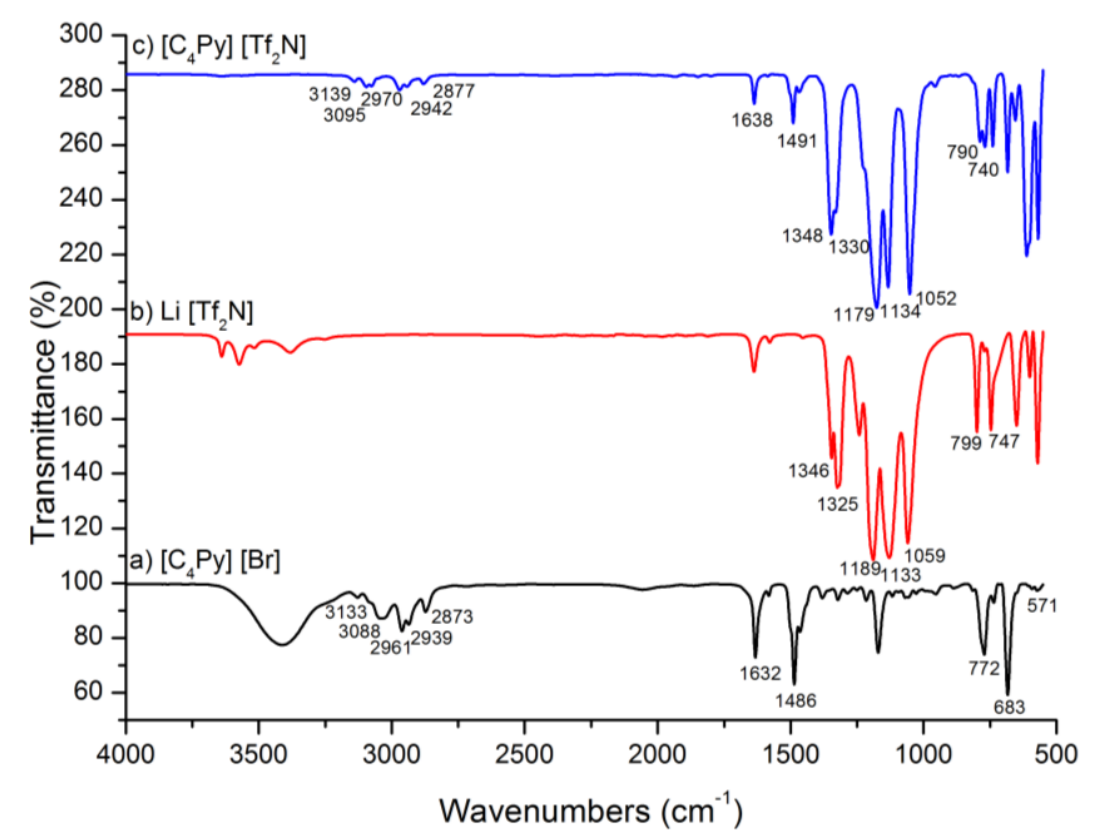

Fig. 1. FTIR spectra for (a) $\left[\mathrm{C}_{4} \mathrm{Py}\right][\mathrm{Br}] ;$ (b) $\mathrm{Li}_{[}\left[\mathrm{Tf}_{2} \mathrm{~N}\right]$; (c) $\left[\mathrm{C}_{4} \mathrm{Py}\right]\left[\mathrm{Tf}_{2} \mathrm{~N}\right]$

Table 1

Summary FTIR spectra bands of $\left[\mathrm{C}_{4} \mathrm{Py}\right]\left[\mathrm{Tf}_{2} \mathrm{~N}\right]$

\begin{tabular}{ll}
\hline Band Assigned & Wavelength $\left(\mathrm{cm}^{-1}\right)$ \\
\hline Aromatic C-H & 3139,3095 \\
Aliphatic C-H & $2970,2942,2877$ \\
Aromatic C-C & 1638 \\
$-\mathrm{CH}_{3}$ & 1491 \\
$\mathrm{C}_{3} \mathrm{SO}_{2}-\mathrm{N}$ & $1348,1330,1134$ \\
$-\mathrm{CF}_{3}$ & 1179 \\
$\mathrm{~S}=\mathrm{O}$ & 1052 \\
$\mathrm{Combination}$ of C-S and S-N & 790 \\
$\mathrm{~S}-\mathrm{N}$ & 740 \\
\hline
\end{tabular}

\subsubsection{NMR spectroscopy}

The synthesized IL, 1-butylpyridinium bis (trifluoromethylsulfonyl) imide, $\left[\mathrm{C}_{4} \mathrm{Py}\right]\left[\mathrm{Tf}_{2} \mathrm{~N}\right]$ was characterized by the proton and carbon NMR ( ${ }^{1} \mathrm{H}$ NMR and $\left.{ }^{13} \mathrm{C} N \mathrm{NMR}\right)$ to evaluate purity and chemical structure of the samples in deuterated methanol (MeOD) solvent. Based on the structure, the total number of Hydrogen and Carbon atoms is 14 and 11 respectively. Both ${ }^{1} \mathrm{H} N M R$ and ${ }^{13} \mathrm{C}$ NMR spectrum of $\left[\mathrm{C}_{4} \mathrm{Py}\right]\left[\mathrm{Tf}_{2} \mathrm{~N}\right]$ ionic liquid is shown in Figure 2, further demonstrated its structure. In the ${ }^{1} \mathrm{H}$ NMR spectrum (Figure 2(a)), the chemical shift peaks at $8.593 \mathrm{ppm}, 8.585 \mathrm{ppm}$ and $8.099 \mathrm{ppm}$ are related to aromatic pyridine ring (assigned as C5 to C9). The chemical shift peaks of C5 and C6 is the same because of their share with the same environment based on the structure. The same concept applied for $\mathrm{C} 7$ and $\mathrm{C} 8$. The peak at $4.630 \mathrm{ppm}$ is assigned for $\mathrm{N}-\mathrm{CH}_{2}$ bond (C4) while the peaks at 1.414 ppm and 2.008 ppm were assigned for $\mathrm{CH}_{2}$ bond (named $\mathrm{C} 2$ and $\mathrm{C} 3$ ). Lastly, the chemical shift peaks at $0.998 \mathrm{ppm}$ is referred to $\mathrm{CH}_{3}$ bond and is assigned as $\mathrm{C} 1$. In the ${ }^{13} \mathrm{C}$ NMR spectrum (Figure 2(b)), the chemical shift peaks at $143.95 \mathrm{ppm}, 142.99 \mathrm{ppm}$ and $126.62 \mathrm{ppm}$ are related to aromatic pyridine ring (C5-C9). For the peaks at $119.57 \mathrm{ppm}$ is referred to carbon in bis (trifluoromethylsulfonyl) imide $\left[\mathrm{Tf}_{2} \mathrm{~N}\right]$ (assigned as $\mathrm{C} 10$ and $\mathrm{C} 11$ ). The peak at $60.06 \mathrm{ppm}$ is assigned to $\mathrm{N}-\mathrm{CH}_{2}$. The peak at $31.47 \mathrm{ppm}$ and $17.48 \mathrm{ppm}$ is related to $\mathrm{CH} 2$ (C2 and $\mathrm{C} 3$ ) and at $10.80 \mathrm{ppm}$ is attributed to $\mathrm{CH} 3$ (C1). All the NMR 
data of $\left[\mathrm{C}_{4} \mathrm{Py}\right]\left[\mathrm{TF}_{2} \mathrm{~N}\right]$ IL presented shows close similarity between chemical shift reported by Yunus et al., [36]. The summary for NMR spectroscopy $\left({ }^{1} \mathrm{H}\right.$ NMR and $\left.{ }^{13} \mathrm{C} \mathrm{NMR}\right)$ for $\left[\mathrm{C}_{4} \mathrm{Py}\right]\left[\mathrm{Tf}_{2} \mathrm{~N}\right] \mathrm{IL}$ are as follows

- ${ }^{1} \mathrm{H}$ NMR (500MHz, MeOD): $\delta 0.998\left[\mathrm{t}, 3 \mathrm{H}, \mathrm{CH}_{3}\right], \delta 1.414\left[\mathrm{~m}, 2 \mathrm{H}, \mathrm{CH}_{2}\right], \delta 2.008\left[\mathrm{~m}, 2 \mathrm{H}, \mathrm{CH}_{2}\right], \delta$ $4.630\left[\mathrm{t}, 2 \mathrm{H}, \mathrm{N}-\mathrm{CH}_{2}\right], \delta 8.099[\mathrm{t}, 2 \mathrm{H}, \mathrm{Py}], \delta 8.585$ [t, 1H, Py], $\delta 8.953$ [d, 2H, Py]. Yield:83\%

- ${ }^{13} \mathrm{C}$ NMR $(125 \mathrm{MHz}, \mathrm{MeOD}): \delta 143.95,142.99,126.62,119.57,60.06,31.47,17.48,10.80$. Yield: $87 \%$

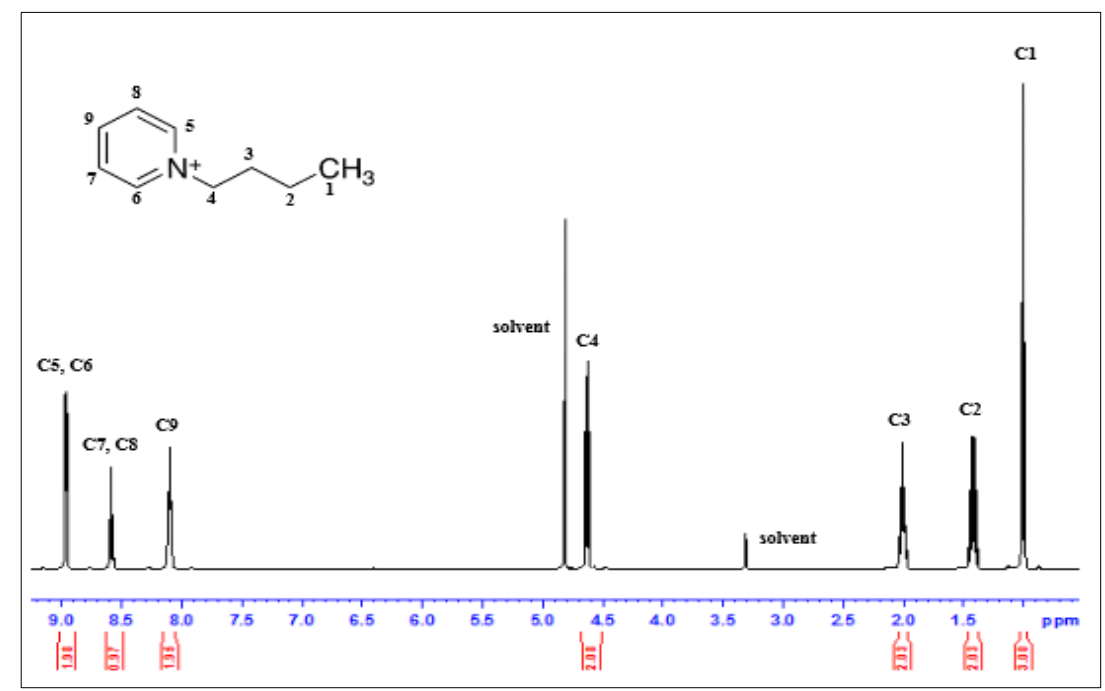

(a)

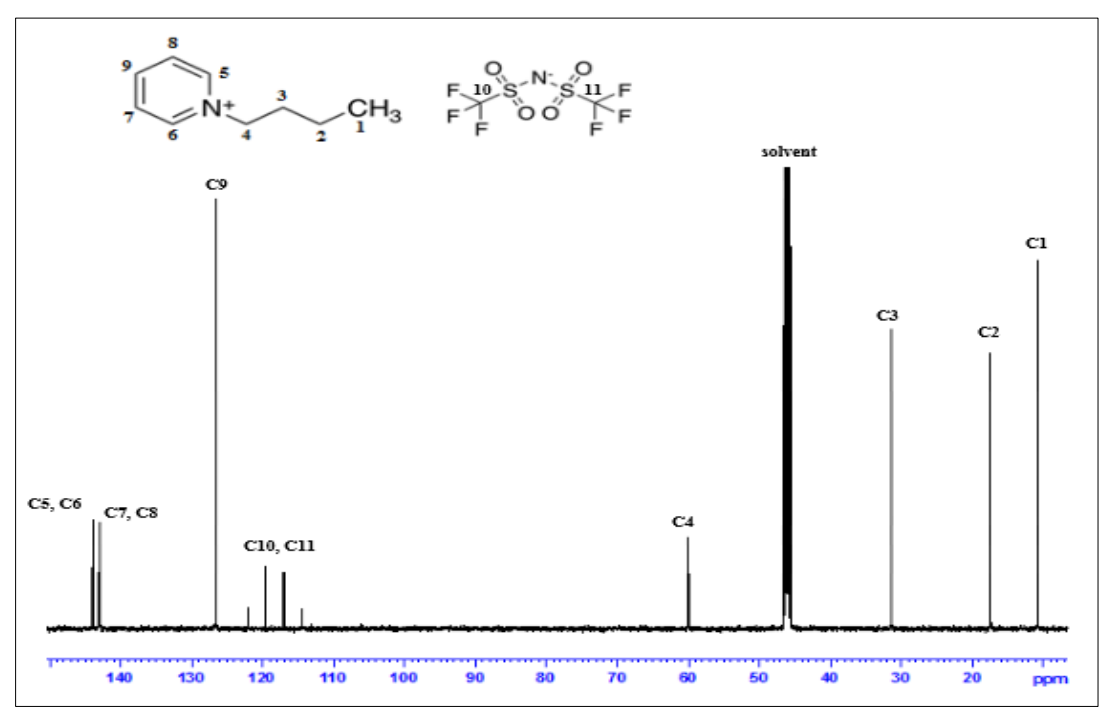

(b)

Fig. 2. (a) ${ }^{1} \mathrm{H} N M R(b){ }^{13} \mathrm{C} N M R$ of $\left[\mathrm{C}_{4} \mathrm{Py}\right]\left[\mathrm{Tf}_{2} \mathrm{~N}\right] \mathrm{IL}$

\subsection{Characterization of Synthesized Activated Carbon}

\subsubsection{BET surface area}

Table 2 shows the summary of the preparation conditions and synthesized AC produced from RSS impregnated with IL. During carbonization, all the moisture, volatile matter and non-carbon are removed to develop porosity and surface area to enhance their adsorption capacity [7]. Besides, the concentration and carbonization temperature play an important role in the production of AC. From the table, the $S_{B E T}$ of raw RSS is $19.6575 \mathrm{~m}^{2} / g$ and $V_{T}$ is $0.0020 \mathrm{~cm}^{3} / g$. After carbonization at $500^{\circ} \mathrm{C}$, 
sample $\mathrm{AC} 1$ at $1 \%$ IL concentration shows an increase of $\mathrm{S}_{\mathrm{BET}}$ and total pore volume, $\mathrm{V}_{\mathrm{T}}$ which are $107.5465 \mathrm{~m}^{2} / \mathrm{g}$ and $0.0451 \mathrm{~cm}^{3} / \mathrm{g}$ compared to sample AC10 at $10 \%$ IL concentration where $\mathrm{S}_{\mathrm{BET}}$ and $\mathrm{V}_{\mathrm{T}}$ are decreased drastically to $0.0113 \mathrm{~m}^{2} / \mathrm{g}$ and $0 \mathrm{~cm}^{3} / \mathrm{g}$, respectively. A similar trend was observed as reported by Azry et al., [6], as the impregnation ratio (IR) increases, the surface area decreases. From their study uses sawdust and phosphoric acid, $\mathrm{H}_{3} \mathrm{PO}_{4}$ as their precursor and activating agent, the $S_{\text {BET }}$ decreases from $1135.624 \mathrm{~m}^{2} / \mathrm{g}$ to $399.013 \mathrm{~m}^{2} / \mathrm{g}$ at IR of $1: 1$ to $1: 3$ and temperature of $500^{\circ} \mathrm{C}$ for 30 minutes. This is due to the maximum amount of acid covering all the surface thus inhibit contact with the sample surface and lowering the activation process. In this study, AC10 shows this phenomenon as it $\mathrm{S}_{\mathrm{BET}}$ and $\mathrm{V}_{\mathrm{T}}$ are decreased due to the excessive IL filled up the pores on the surface and completely blocked the pore, thus slow down the activation process to form pores [5]. It can conclude, IL functions as an activating agent to create new pores at low concentrations. Additionally, after increase temperature at $800^{\circ} \mathrm{C}$, the sample AC2 shows the highest $\mathrm{S}_{\mathrm{BET}}$ and $\mathrm{V}_{\mathrm{T}}$ which are $392.8927 \mathrm{~m}^{2} / \mathrm{g}$ and $0.2059 \mathrm{~cm}^{3} / \mathrm{g}$ respectively. This is because all the volatile matter had been released and develop more pores at a high temperature. Sample AC2 can be considered as a better adsorbent for $\mathrm{CO}_{2}$ adsorption.

Table 2

Surface Area and Porosity of Raw RSS and Synthesized AC

\begin{tabular}{lllll}
\hline Sample Name & $\begin{array}{l}\text { Temperature } \\
\left({ }^{\circ} \mathrm{C}\right)\end{array}$ & Concentration $(\%)$ & $\begin{array}{l}\text { Specific Surface Area, } \\
\text { Sbet }\left(\mathrm{m}^{2} / \mathrm{g}\right)\end{array}$ & $\begin{array}{l}\text { Total Pore Volume, } \\
\mathrm{Vt}\left(\mathrm{cm}^{3} / \mathrm{g}\right)\end{array}$ \\
\hline Raw RSS & - & - & 19.6575 & 0.0020 \\
AC1 & 500 & 1 & 107.5465 & 0.0451 \\
AC2 & 800 & 1 & 392.8927 & 0.2059 \\
AC10 & 500 & 10 & 0.0113 & 0 \\
\hline
\end{tabular}

\subsubsection{FESEM analysis}

In order the verify the surface area and porosity in Table 2, FESEM analysis was conducted to observe the surface morphology of raw RSS and synthesized AC ( $A C 1, A C 2$ and AC10). Besides, the efficiency of adsorption capacity can be determined from the surface morphology. As shown in Figure $3(a)$, the morphology of raw RSS is irregularly shaped, rough and very low pores on the surface of a precursor. After carbonization, sample AC1 had a very few pores at temperature $500^{\circ} \mathrm{C}$ as shown in Figure 3(b). This shows the development of pores still an early stage as the activation rate is low at this temperature. As the activation temperature increased at $800^{\circ} \mathrm{C}$, sample $A C 2$ shows more pores rapidly developed as in Figure 3(c). The formation of pores in $\mathrm{AC} 2$ would help for $\mathrm{CO}_{2}$ diffuse into the pores thus increase the $\mathrm{CO}_{2}$ adsorption capacity. This agrees well as sample AC2 has the highest $\mathrm{S}_{\mathrm{BET}}$ and $\mathrm{V}_{\mathrm{T}}$. Besides, the high concentration of IL caused a coating on the surface of AC10 and completely blocked the formation of pore including preventing from $\mathrm{CO}_{2}$ adsorption process to occur. The surface morphology of AC10 is shown as Figure 3(d). 


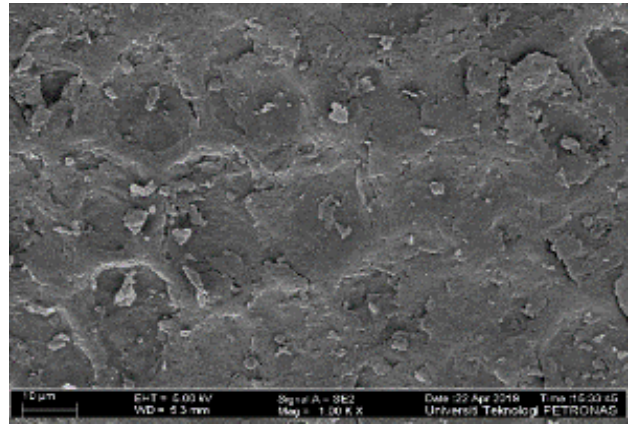

(a)

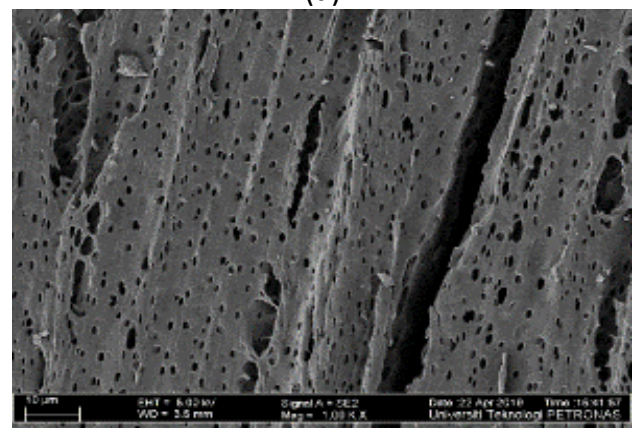

(c)

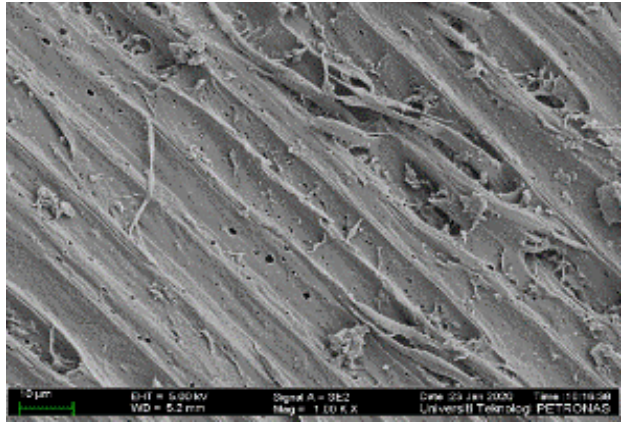

(b)

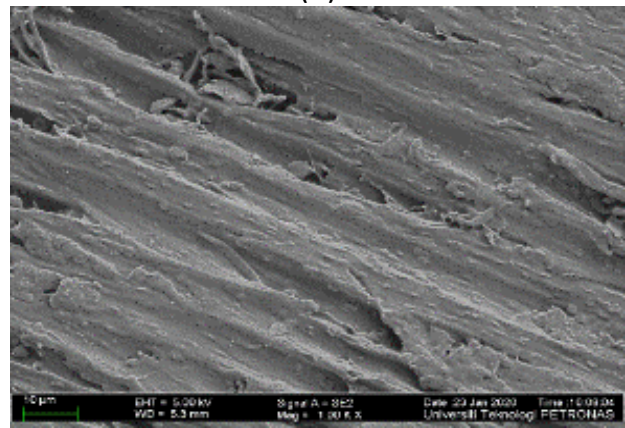

(d)

Fig. 3. FESEM Analysis at magnification of $1000 \mathrm{X}$ (a) Raw RSS (b) AC1 at $1 \%$ IL concentration at $500^{\circ} \mathrm{C}$ (c) AC2 at $1 \%$ IL concentration at $800^{\circ} \mathrm{C}$ (d) AC10 at $10 \% \mathrm{IL}$ concentration at $500^{\circ} \mathrm{C}$

\section{3 $\mathrm{CO}_{2}$ Adsorption Analysis}

The $\mathrm{CO}_{2}$ adsorption capacity test for each sample was conducted at $25^{\circ} \mathrm{C}$ and 1 bar and shown in Figure 4. The highest $\mathrm{CO}_{2}$ adsorption capacity was observed in sample $\mathrm{AC} 2$ at $50.783 \mathrm{~cm}^{3} / \mathrm{g}$, followed by $\mathrm{AC} 1$ at $33.927 \mathrm{~cm}^{3} / \mathrm{g}$ and $\mathrm{AC} 10$ at $10.022 \mathrm{~cm}^{3} / \mathrm{g}$. AC2 contributes to the highest $\mathrm{CO}_{2}$ adsorption capacity because it has a high surface area compared to AC1 and AC10. A high surface area allows $\mathrm{CO}_{2}$ to diffuse into the pores of $\mathrm{AC}$ [28]. Additionally, the performance of $\mathrm{CO}_{2}$ adsorption capacity of sample AC2 in this study also is compared with other published literature. From these, it can be seen that sample AC2 has higher adsorption capacity compared to Norit ${ }^{\circledR}$ SX2 (commercial AC) at 42.112 $\mathrm{cm}^{3} / \mathrm{g}$ and palm kernel shell (PKS) AC at $47.712 \mathrm{~cm}^{3} / \mathrm{g}$. The highest $\mathrm{CO}_{2}$ adsorption capacity is bamboo $\mathrm{AC}$ at $67.200 \mathrm{~cm}^{3} / \mathrm{g}$ followed by rice husk $\mathrm{AC}$ at $69.440 \mathrm{~cm}^{3} / \mathrm{g}$. From Figure 4 , it can concluded that the $\mathrm{CO}_{2}$ adsorption capacity of sample $\mathrm{AC} 2$ is comparable with other biomass materials. 


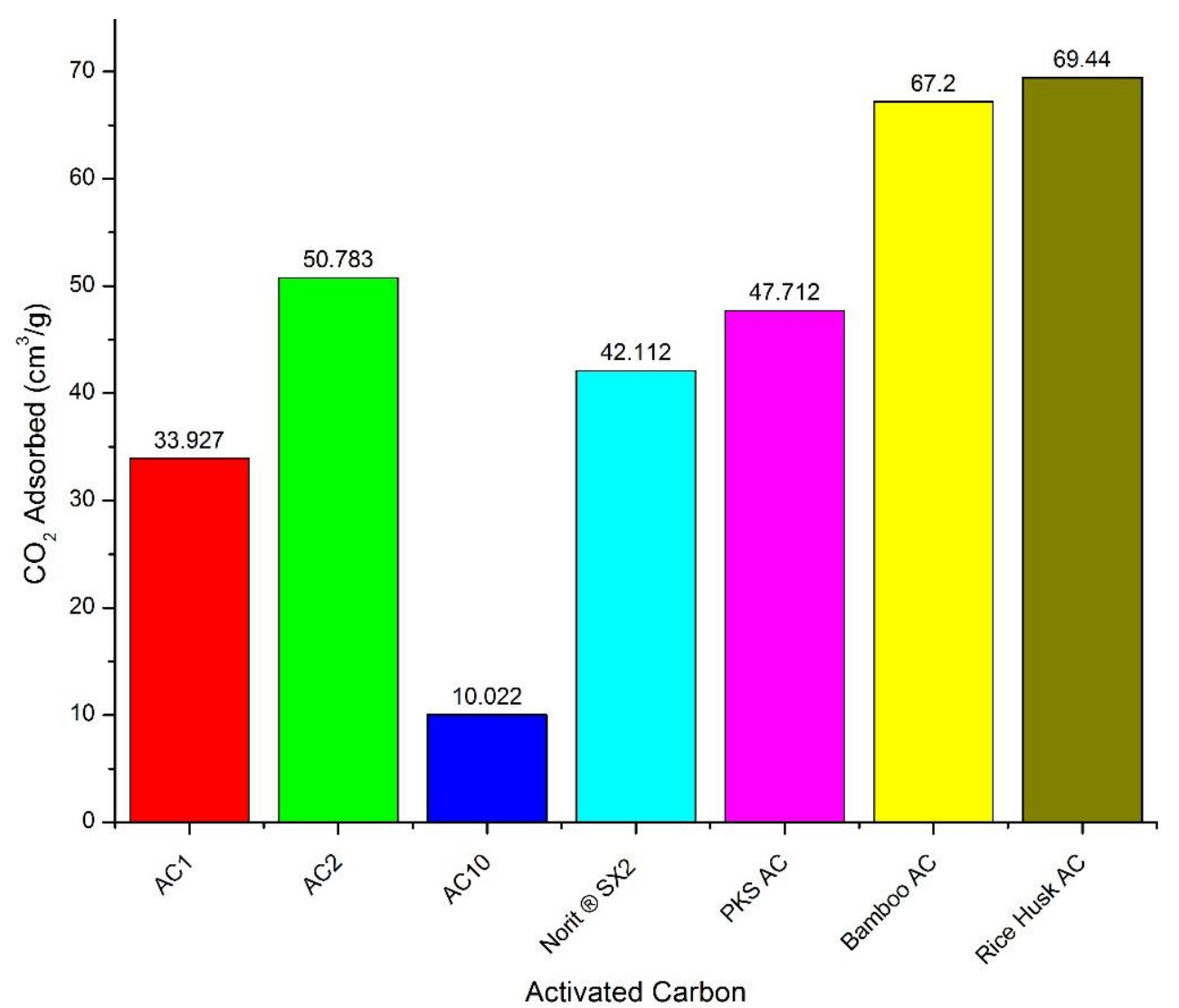

Fig. 4. $\mathrm{CO}_{2}$ Adsorption Capacity at $25^{\circ} \mathrm{C}$ and 1 bar $[19,29,35]$

\section{Conclusion}

As a conclusion, the pyridinium based IL, 1-butylpyridinium bis (trifluoromethylsulfonyl) imide, $\left[\mathrm{C}_{4} \mathrm{Py}\right]\left[\mathrm{Tf}_{2} \mathrm{~N}\right]$ was successfully synthesized and can be used as an activating agent in the production of activated carbon due to it can promote porous carbonaceous structure during carbonization and also can enhance the performance of $\mathrm{CO}_{2}$ adsorption. The sample AC2 contributes to the highest surface area and total pore volume at a low concentration of IL. Moreover, its performance is tested with a static volumetric instrument and shows the highest $\mathrm{CO}_{2}$ adsorption capacity. Therefore, it can conclude that a low concentration of IL could minimize the use of IL in which offers low-cost and green technology towards $\mathrm{CO}_{2}$ capture application.

\section{Acknowledgements}

This work was supported by Yayasan Universiti Teknologi PETRONAS (YUTP-FRG 015LCO-068). The authors also gratefully acknowledge Universiti Teknologi PETRONAS for the technical and facilities support. Support from the Ministry of Education Malaysia through the HICOE award to Centre for Biofuel and Biochemical Research (CBBR) is also acknowledged.

\section{References}

[1] Ahmed, Rafay, Guijian Liu, Balal Yousaf, Qumber Abbas, Habib Ullah, and Muhammad Ubaid Ali. "Recent advances in carbon-based renewable adsorbent for selective carbon dioxide capture and separation-A review." Journal of Cleaner Production 242 (2020): 118409. https://doi.org/10.1016/i.jclepro.2019.118409

[2] Bergna, Davide, Toni Varila, Henrik Romar, and Ulla Lassi. "Comparison of the properties of activated carbons produced in one-stage and two-stage processes." C-Journal of Carbon Research 4, no. 3 (2018): 41. https://doi.org/10.3390/c4030041 
[3] Bohli, Thouraya, Abdelmottaleb Ouederni, Nuria Fiol, and Isabel Villaescusa. "Evaluation of an activated carbon from olive stones used as an adsorbent for heavy metal removal from aqueous phases." Comptes Rendus Chimie 18, no. 1 (2015): 88-99. https://doi.org/10.1016/j.crci.2014.05.009

[4] Azry, Borhan, and Fikree Kamil Ahmad. "Preparation and characterization of activated carbon from rubber-seed shell by chemical activation." Journal of Applied Sciences 12, no. 11 (2012): 1124-1129. https://doi.org/10.3923/jas.2012.1124.1129

[5] Borhan, Azry, Suzana Yusup, Jun Wei Lim, and Pau Loke Show. "Characterization and modelling studies of activated carbon produced from rubber-seed shell using $\mathrm{KOH}$ for $\mathrm{CO}_{2}$ adsorption." Processes 7, no. 11 (2019): 855. https://doi.org/10.3390/pr7110855

[6] Azry, Borhan, TongYeong Yit, Yusup Suzana, and Mohd Yunus Normawati. "Monoethanolamine wastewater treatment via adsorption using wood sawdust based activated carbon." Malaysian Journal of Analytical Sciences 22, no. 3 (2018): 532-541. https://doi.org/10.17576/mjas-2018-2203-22

[7] Contescu, Cristian I., Shiba P. Adhikari, Nidia C. Gallego, Neal D. Evans, and Bryan E. Biss. "Activated carbons derived from high-temperature pyrolysis of lignocellulosic biomass." C-Journal of Carbon Research 4, no. 3 (2018): 51. https://doi.org/10.3390/c4030051

[8] Danish, Mohammed, and Tanweer Ahmad. "A review on utilization of wood biomass as a sustainable precursor for activated carbon production and application." Renewable and Sustainable Energy Reviews 87 (2018): 1-21. https://doi.org/10.1016/j.rser.2018.02.003

[9] Enayati, Maedeh, and Hossein Faghihian. "N-butyl-pyridinium tetrafluoroborate as a highly efficient ionic liquid for removal of dibenzothiophene from organic solutions." Journal of Fuel Chemistry and Technology 43, no. 2 (2015): 195-201.

[10] Fan, Xiangqian, Lingxia Zhang, Guobin Zhang, Zhu Shu, and Jianlin Shi. "Chitosan derived nitrogen-doped microporous carbons for high performance $\mathrm{CO}_{2}$ capture." Carbon 61 (2013): 423-430. https://doi.org/10.1016/i.carbon.2013.05.026

[11] Furmanski, Luana Milak, Patricia Darolt de Costa, and Lucas Dominguini. "Production of Activated Carbon from Nutshell as An Alternative Material for Adsorption of Methylene Blue." In XIV Brazil MRS Meeting, Rio de Janeiro, RJ (2015).

[12] González-García, P. "Activated carbon from lignocellulosics precursors: A review of the synthesis methods, characterization techniques and applications." Renewable and Sustainable Energy Reviews 82 (2018): 1393-1414. https://doi.org/10.1016/i.rser.2017.04.117

[13] Guo, Yafei, Chang Tan, Jian Sun, Weiling Li, Jubing Zhang, and Chuanwen Zhao. "Porous activated carbons derived from waste sugarcane bagasse for $\mathrm{CO}_{2}$ adsorption." Chemical Engineering Journal 381 (2020): 122736. https://doi.org/10.1016/j.cej.2019.122736

[14] Habila, Mohamed A., Zeid A. AlOthman, Ayman A. Ghfar, Maha IM Al-Zaben, Ahmed AS Alothman, Ahmed A. Abdeltawab, Adel El-Marghany, and Mohamed Sheikh. "Phosphonium-based ionic liquid modified activated carbon from mixed recyclable waste for mercury (II) uptake." Molecules 24, no. 3 (2019): 570.

[15] He, Xiaodong, Jiamei Zhu, Hongmin Wang, Min Zhou, and Shuangquan Zhang. "Surface Functionalization of Activated Carbon with Phosphonium Ionic Liquid for $\mathrm{CO}_{2}$ Adsorption." Coatings 9, no. 9 (2019): 590. https://doi.org/10.3390/coatings9090590

[16] Hernández-Montoya, Virginia, Josafat García-Servin, and José Iván Bueno-López. "Thermal treatments and activation procedures used in the preparation of activated carbons." Lignocellulosic Precursors Used in the Synthesis of Activated Carbon-Characterization Techniques and Applications in the Wastewater Treatment (2012): 19-36. https://doi.org/10.5772/39365

[17] Kemp, K. Christian, Seung Bin Baek, Wang-Geun Lee, M. Meyyappan, and Kwang S. Kim. "Activated carbon derived from waste coffee grounds for stable methane storage." Nanotechnology 26, no. 38 (2015): 385602.

[18] Lee, Je Seung, Xiqing Wang, Huimin Luo, and Sheng Dai. "Fluidic carbon precursors for formation of functional carbon under ambient pressure based on ionic liquids." Advanced Materials 22, no. 9 (2010): 1004-1007. https://doi.org/10.1002/adma.200903403

[19] Li, Ming, and Rui Xiao. "Preparation of a dual pore structure activated carbon from rice husk char as an adsorbent for $\mathrm{CO}_{2}$ capture." Fuel Processing Technology 186 (2019): 35-39. https://doi.org/10.1016/i.fuproc.2018.12.015

[20] Murshid, Ghulam, Azmi Mohd Shariff, Lau Kok Keong, and A. M. Bustam. "Thermo physical analysis of 2-amino-2methyl-1-propanol solvent for carbon dioxide removal." Chemical Engineering Transactions 25 (2011): 45-50.

[21] Nandiyanto, Asep Bayu Dani, Zulfan Adi Putra, Riezqa Andika, Muhammad Roil Bilad, Tedi Kurniawan, Rizka Zulhijah, and Ida Hamidah. "Porous activated carbon particles from rice straw waste and their adsorption properties." Journal of Engineering Science and Technology 12, no. Specia (2017): 1-11. 
[22] Sugumaran, P., V. Priya Susan, P. Ravichandran, and S. Seshadri. "Production and characterization of activated carbon from banana empty fruit bunch and Delonix regia fruit pod." Journal of Sustainable Energy \& Environment 3, no. 3 (2012): 125-132.

[23] Paraknowitsch, Jens Peter, and Arne Thomas. "Functional Carbon Materials from lonic Liquid Precursors." Chemical Synthesis and Applications of Graphene and Carbon Materials (2017): 21-42. https://doi.org/10.1002/9783527648160.ch2

[24] Pârvulescu, Vasile I., and Christopher Hardacre. "Catalysis in ionic liquids." Chemical Reviews 107, no. 6 (2007): 2615-2665. https://doi.org/10.1021/cr050948h

[25] Plaza, M. G., C. Pevida, J. J. Pis, and F. Rubiera. "Evaluation of the cyclic capacity of low-cost carbon adsorbents for $\begin{array}{lllllll}\text { post-combustion } \quad \mathrm{CO}_{2} & \text { capture." } & \text { Energy } & \text { Procedia } & 4 & \text { (2011): }\end{array}$ https://doi.org/10.1016/i.egypro.2011.01.178

[26] Poole, Colin F., and Salwa K. Poole. "Extraction of organic compounds with room temperature ionic liquids." Journal of Chromatography A 1217, no. 16 (2010): 2268-2286. https://doi.org/10.1016/i.chroma.2009.09.011

[27] Ramesh, S., and Soon-Chien Lu. "Effect of nanosized silica in poly (methyl methacrylate)-lithium bis (trifluoromethanesulfonyl) imide based polymer electrolytes." Journal of Power Sources 185, no. 2 (2008): 14391443.

[28] Rashidi, NOR Adilla, Suzana Yusup, and Azry Borhan. Novel low-cost activated carbon from coconut shell and its adsorptive characteristics for carbon dioxide. Vol. 594. Trans Tech Publications Ltd, 2014. https://doi.org/10.4028/www.scientific.net/KEM.594-595.240

[29] Rashidi, Nor Adilla, and Suzana Yusup. "Potential of palm kernel shell as activated carbon precursors through single stage activation technique for carbon dioxide adsorption." Journal of Cleaner Production 168 (2017): 474-486. https://doi.org/10.1016/i.jclepro.2017.09.045

[30] Rashidi, Nor Adilla, Suzana Yusup, and Azry Borhan. "Isotherm and thermodynamic analysis of carbon dioxide on activated carbon." Procedia Engineering 148 (2016): 630-637. https://doi.org/10.1016/i.proeng.2016.06.527

[31] Sun, Kang, and Jian chun Jiang. "Preparation and characterization of activated carbon from rubber-seed shell by physical activation with steam." Biomass and Bioenergy 34, no. 4 (2010): 539-544.

[32] Torralba-Calleja, Elena, James Skinner, and David Gutiérrez-Tauste. " $\mathrm{CO}_{2}$ capture in ionic liquids: a review of solubilities and experimental methods." Journal of Chemistry 2013 (2013). https://doi.org/10.1155/2013/473584

[33] Wang, Qijun, Yuanxin Wu, and Shengdong Zhu. "Use of ionic liquids for improvement of cellulosic ethanol production." BioResources 6, no. 1 (2011): 1-2.

[34] Wang, Xue, Shaojuan Zeng, Junli Wang, Dawei Shang, Xiangping Zhang, Jindun Liu, and Yatao Zhang. "Selective separation of hydrogen sulfide with pyridinium-based ionic liquids." Industrial \& Engineering Chemistry Research 57, no. 4 (2018): 1284-1293. https://doi.org/10.1021/acs.iecr.7b04477

[35] Wang, Yuxin, Yaping Zhou, Congmin Liu, and Li Zhou. "Comparative studies of $\mathrm{CO}_{2}$ and $\mathrm{CH} 4$ sorption on activated carbon in presence of water." Colloids and Surfaces A: Physicochemical and Engineering Aspects 322, no. 1-3 (2008): 14-18. https://doi.org/10.1016/j.colsurfa.2008.02.014

[36] Yunus, Normawati M., MI Abdul Mutalib, Zakaria Man, Mohamad Azmi Bustam, and Thanapalan Murugesan. "Thermophysical properties of 1-alkylpyridinum bis (trifluoromethylsulfonyl) imide ionic liquids." The Journal of Chemical Thermodynamics 42, no. 4 (2010): 491-495. https://doi.org/10.1016/j.jct.2009.11.004

[37] Zhang, Suojiang, Ning Sun, Xuezhong He, Xingmei Lu, and Xiangping Zhang. "Physical properties of ionic liquids: database and evaluation." Journal of Physical and Chemical Reference Data 35, no. 4 (2006): 1475-1517. https://doi.org/10.1063/1.2204959

[38] Zhang, Yaqin, Hongyan He, Suojiang Zhang, and Maohong Fan. "Hydrogen-bonding interactions in pyridinium-based ionic liquids and dimethyl sulfoxide binary systems: a combined experimental and computational study." ACS Omega 3, no. 2 (2018): 1823-1833. https://doi.org/10.1021/acsomega.7b01805 